\title{
Synthesis and Characterization of Newly Synthesized Thiosemicarbazone Ligands with IR, NMR and Mass Spectral Techniques
}

\author{
N. RAMA JYOTHI ${ }^{\star}$ and N. A. MOHAMED FAROOK \\ Department of Chemistry, Khadir Mohideen College, Adirampattinam, Tamilnadu-614701, India. \\ *Corresponding author E-mail: ramadasaradhi@gmail.com \\ http://dx.doi.org/10.13005/ojc/35Specialissue106
}

(Received: November 01, 2018; Accepted: March 18, 2019)

\begin{abstract}
Among various organic chelating agents thiosemicarbazones occupy an important role due to their efficiency towards many metal ions through thionate sulphur atom and hydrazino nitrogen atom. Thiosemicarbazones can be obtained by condensing thiosemicarbazide with various carbonyl compounds. In recent years, the usage of thiosemicarbazone ligands has been reported by so many authors in the fields of analytical and biological. The present study reported about of two newly synthesized thiosemicarbazone ligands, namely 2,3,4-trihydroxybenzaldehyde4-phenylthiosemicarbazone (THBPTSC) and 2,3,4-trihydroxybenzaldehyde-4-methylthiosemi carbazone (THBMTSC). These two new ligands are characterized with various spectral techniques, such as FT-IR, NMR and mass spectral techniques. The elemental composition was checked with elemental analysis report. Molar conductivity measurements of the ligands also reported.
\end{abstract}

Keywords: Thiosemicarbazones, 2,3,4-trihydroxybenzaldehyde-4-phenylthiosemicarbazone, 2,3,4-trihydroxybenzaldehyde-4-methylthiosemicarbazone, FT-IR, NMR, Mass spectra.

\section{INTRODUCTION}

Organic chelating agents play a vital role in both analytical and biological fields. Among the various organic chelating agents, thiosemicarbazones are very important groups because of their wide applications. Thiosemicarbazones are having a great biological activities due to their ability to coordinate to the metal centers in enzymes. A number of studies reveals the biological and pharmacological activities of thiosemicarbazones and their metal complexes, such as antimicrobial, antimalarial, antiviral, antitumor and anti-HIV activities.

In recent years so many authors reported biological and analytical applications of thiosemicarbazones and/or their metal complexes. Salsi et al., ${ }^{1}$ reported anti-trypanosoma activity of thiosemicarbazones derived from fluorinated benzoylthioureas. Sens et al., ${ }^{2}$ reported the synthesis of new thiosemicarbazones which were acted as inhibitors of Mycobacterium tuberculosis protein

This is an Open Access article licensed under a Creative Commons license: Attribution 4.0 International (CC- BY). Published by Oriental Scientific Publishing Company @ 2018 
tyrosine phosphate A. Deng et al., ${ }^{3}$ reported the anticancer property of copper complexes of 2-pyridine thiosemicarbazone ligands. A few studies ${ }^{4-7}$ reported about the analytical and biological properties of thiosemicarbazones. Antimicrobial activity of thiosemicarbazones and their metal complexes were studied by Ibrahim et al., ${ }^{8,9}$ and Temraz et al., ${ }^{10}$. Kalinowski et al., ${ }^{11}$ was reported the importance of thiosemicarbazones in cancer treatment. Matesanz and Souza ${ }^{12}$ reviewed about the antitumor activity of thiosemicarbazone ligands.

This paper describes synthesis and characterization of two new ligands namely, 2,3,4trihydroxybenzaldehyde-4-phenylthiosemicarbazone (THBPTSC) and 2,3,4-trihydroxybenzalde-hyde-4methylthiosemicarbazone (THBMTSC). These newly synthesized chelating agents were characterized with elemental analysis, molar conductivity measurement, FT-IR, NMR, and mass spectra.

\section{EXPERIMENTAL}

\section{Chemicals}

The chemicals used in this study was all are pure analytical grade. A Fisher-scientific stirrer was used for the stirring of the reactants which contains a hot plate.

\section{Synthesis scheme for 2,3,4-trihydroxybenzal} dehyde-4-phenylthiosemicarbazone (THBPTSC)

Methanolic solutions of $1.54 \mathrm{~g}$ of 2,3,4trihydroxybenzaldehyde (M.Wt. $303.35 \mathrm{~g}$ ) in $100 \mathrm{~mL}$ and $1.67 \mathrm{~g}$ of 4-phenylthiosemicarbazide (M.Wt. $105.16 \mathrm{~g}$ ) in $100 \mathrm{~mL}$ were refluxed nearly $4 \mathrm{~h}$ in a round bottom flask. The resultant product (yield, $79 \%$ ) was separated by filtration and then it was dried. The final product was recrystallized once again from methanol. The synthesis scheme of THBPTSC is presented below (Scheme 1).

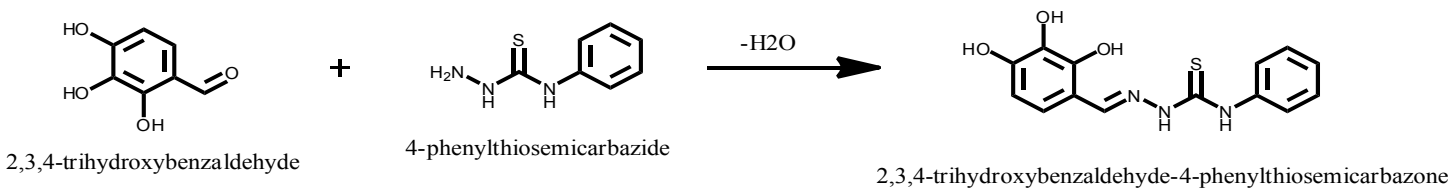

Scheme 1. Synthesis scheme of 2,3,4-trihydroxybenzaldehyde-4-phenylthiosemicarbazone

Synthesis of 2,3,4-trihydroxybenzaldehyde-4methylthiosemicarbazone (THBMTSC)

Synthesis of THBMTSC is presented in Scheme 2. THBMTSC was synthesized by the refluxing of $1.54 \mathrm{~g}$ of 2,3,4-trihydroxybenzldehyde (M.Wt. $303.35 \mathrm{~g}$ ) in methanol and $1.05 \mathrm{~g}$ of 4-methyl-3-thiosemicarbazide (M.Wt. $105.16 \mathrm{~g}$ ) in methanol for nearly $4 \mathrm{~h} 30 \mathrm{~min}$ in a round bottom flask. The resultant product (yield, 84\%) was separated by filtration and then dried. The final product was recrystallized once again with methanol.

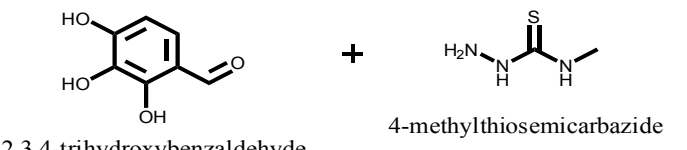

2,3,4-trihydroxybenzaldehyde

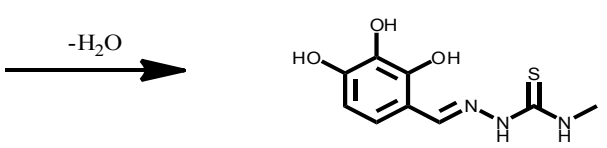

2,3,4-trihydroxybenzaldehyde-4-methylthiosemicarbazone

Scheme 2. Synthesis of 2,3,4-trihydroxybenzaldehyde-4-methylthiosemicarbazone

Characterization of thiosemicarbazones with Elemental Analysis, FT-IR, NMR, and Mass spectra Elemental analysis $(\mathrm{C}, \mathrm{H}, \mathrm{N}$ and $\mathrm{S})$ of THBPTSC and THBMTSC were performed on Thermo Scientific elemental analyzer (Thermo Eager 300 Flash EA1112, USA). Molar conductivity studies were performed with portable molar conductivity meter (MT-115, Manti Lab Solutions, India). FT-IR spectra were recorded on a Nicolet FT-IR 560 Magna spectrometer. High Resolution FAB mass spectra were recorded on a JMS 700 mass spectrometer (JEOL, Tokyo, Japan).

\section{RESULTS AND DISCUSSION}

The synthesized thiosemicarbazone ligands, THBPTSC and THBMTSC are characterized with elemental analysis, molar conductivity measurements and with various spectral techniques, such FTIR, NMR and mass spectra. 


\section{Elemental Analysis}

Elemental analysis reports of both the chelating agents, THBPTSC and THBMTSC are presented in Fig. 1 and 2. The calculated elemental analysis data of THBPTSC $\left(\mathrm{C}_{14} \mathrm{H}_{13} \mathrm{~N}_{3} \mathrm{SO}_{3}\right)$ is C: $55.38 \%$; H: $4.32 \%$; N: $13.84 \%$; S: $10.55 \%$; O: $15.32 \%$. This calculated data is well coincide with the practically obtained values as C: $54.58 \% ; \mathrm{H}: 4.31 \%$; $\mathrm{N}: 12.89 \%$; and S: $11.56 \%$ to above mentioned formula of THBPTSC. The theoretically calculated composition for TCMTSC $\left(\mathrm{C}_{9} \mathrm{H}_{11} \mathrm{~N}_{3} \mathrm{SO}_{3}\right)$, (C: $44.76 \%$; $\mathrm{H}: 4.58 \%$; N: $17.40 \%$; S: $13.26 \%$ and O: $19.89 \%$ ) is well in agreement with the practically found data (C: $45.22 \%$; H: $4.58 \%$; N: $16.33 \%$ and S: $15.29 \%$ )to the above proposed formula for THBMTSC.

\section{Molar conductivity measurements}

Molar conductivity values of THBPTSC and THBMTSC are 27.5 and $30.0 \mathrm{~S} \mathrm{~cm}^{2} \mathrm{~mol}^{-1}$, respectively. This indicates both ligands are having similar conductivity values.

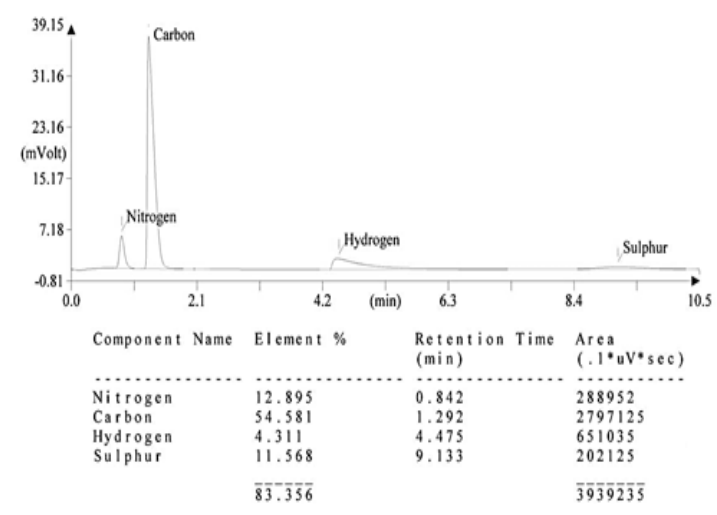

Fig. 1. Elemental analysis report of THBPTSC

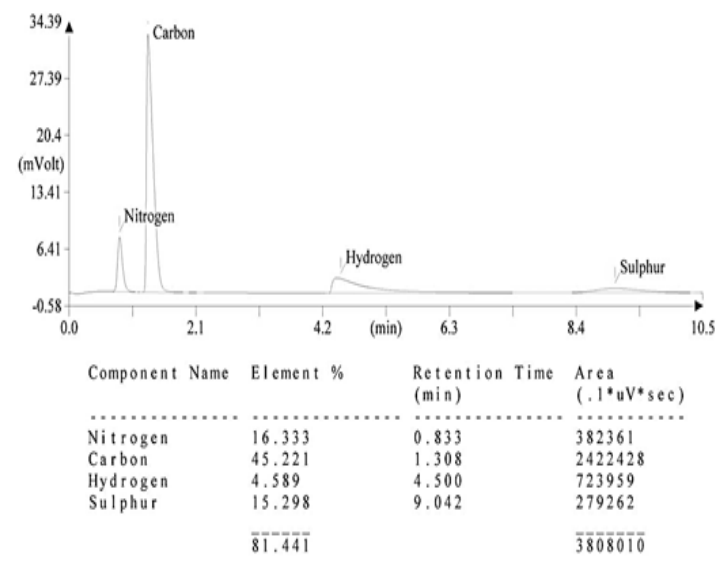

Fig. 2. Elemental analysis report of THBMTSC

\section{FT-IR spectral analysis}

FT-IR spectrum of THBPTSC is presented in Fig. 3. The FT-IR data of THBPTSC is as follows: $\mathrm{C}=\mathrm{N}$ peak appears at $1609 \mathrm{~cm}^{-1}, \mathrm{C}=\mathrm{S}$ peak appears at $1255 \mathrm{~cm}^{-1}$ and $-\mathrm{NH}$ peak appears at $3400 \mathrm{~cm}^{-1}$. This obtained data confirms the formation of the newly synthesized ligand, THBPTSC. FT-IR spectrum of THBMTSC is presented in Fig. 4. FT-IR data of THBMTSC is as follows, $\mathrm{C}=\mathrm{N}$ peak appears at $1630 \mathrm{~cm}^{-1} \mathrm{C}=\mathrm{S}$ peak appears at $1248 \mathrm{~cm}^{-1}$ and $-\mathrm{NH}$ peak appears at $3250 \mathrm{~cm}^{-1}$. This obtained data confirms the formation of the newly synthesized ligand, THBMTSC.

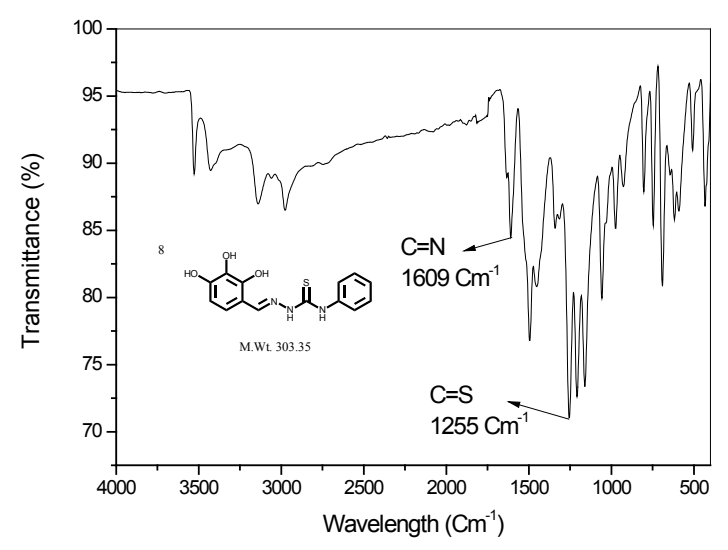

Fig. 3. FT-IR Spectrum of THBPTSC

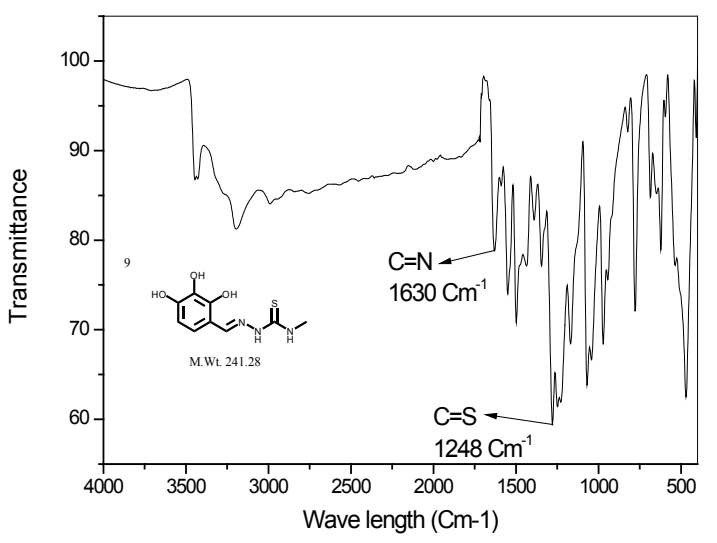

Fig. 4. FT-IR Spectrum of THBMTSC

\section{Proton NMR spectral characterization}

Proton NMR spectrum data (DMSO/TMS) of THBPTSC is obtained as: ${ }^{1} \mathrm{H}$ NMR $(300 \mathrm{MHz}$, DMSO-d6): $d=11.580(\mathrm{~s}, 1 \mathrm{H}), 9.91(\mathrm{~s}, 1 \mathrm{H}), 9.53$ (s, 1H), 9.03 (broad, 1H), $8.45(\mathrm{~s}, 2 \mathrm{H}), 8.34(\mathrm{~s}, 1 \mathrm{H})$, $7.57(\mathrm{~d}, 1 \mathrm{H}), 7.33(\mathrm{~m}, 2 \mathrm{H}), 7.16(\mathrm{t}, 1 \mathrm{H}), 6.35(\mathrm{~d}, 1 \mathrm{H})$. Based on the obtained proton NMR data it is clear 
that the formation of THBPTSC. The proton NMR spectrum of THBPTSC is presented in Fig. 5. The proton NMR spectrum (DMSO/TMS) of THBMTSC is obtained as: $\mathrm{d}=11.22(\mathrm{~s}, 1 \mathrm{H}$; $\mathrm{Ar}-\mathrm{N}-\mathrm{NH}), 9.49$ (broad, $1 \mathrm{H}$; Ar-OH), 8.98 (broad, 1H; Ar-OH), 8.42 (broad, 1H; Ar$\mathrm{OH}), 8.25(\mathrm{~m}, 2 \mathrm{H} ; \mathrm{CH} 3 \mathrm{NH}$ and $\mathrm{Ar}-\mathrm{CH}), 7.14$ (d, J=8.4 $\mathrm{Hz}, 1 \mathrm{H} ; \mathrm{Ar}), 6.34(\mathrm{~d}, \mathrm{~J}=8.4 \mathrm{~Hz}, 1 \mathrm{H} ; \mathrm{Ar}), 2.98(\mathrm{~d}, 3 \mathrm{H}$; $\mathrm{NCH}_{3}$ ). Based on the obtained proton NMR data it is clear that the formation of THBMTSC. The proton NMR spectrum of THBPTSC is presented in Figure 6.

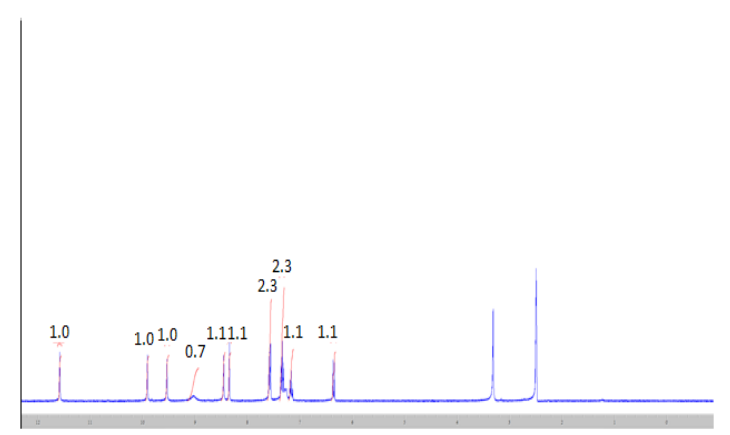

Fig. 5. Proton NMR Spectrum of THBPTSC

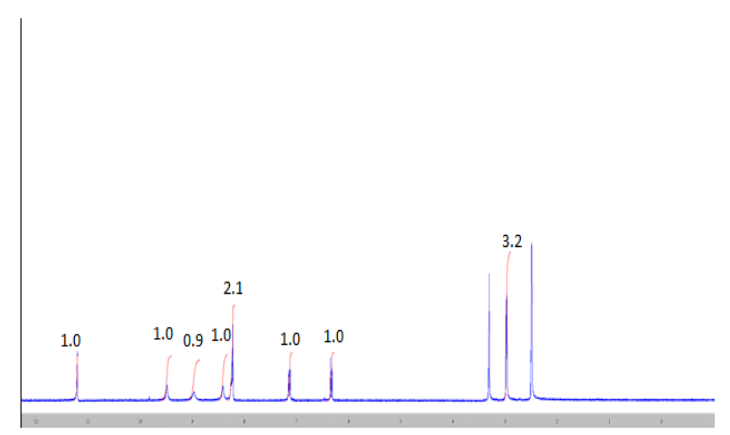

Fig. 6. Proton NMR Spectrum of THBMTSC

\section{CONCLUSION}

This study confirms the formation of two new thiosemicarbazone chelating compounds namely, 2,3,4-trihydroxybenzaldehyde-4-phenylthiosemi carbazone (THBPTSC) and 2,3,4-trihydroxy benzaldehyde-4-methylthiosemicarbazone (THBMTSC). The formation of these two new thiosemi -carbazone chelating compounds was confirmed by the elemental analysis studies and various spectral analysis techniques, as FT-IR, 1 H NMR and mass. These organic

\section{Mass spectral characterization of ligands}

Based on molecular formula the molecular weight of THBPTSC is calculated as 303 . The molecular weight obtained practically with mass spectrum as 304. Based on molecular formula the molecular weight of THBMTSC is calculated as 241 . The molecular weight obtained practically with mass spectrum as 242 . The mass spectra of THBPTSC and THBMTSC are presented in Fig. 7 , 8 , respectively.

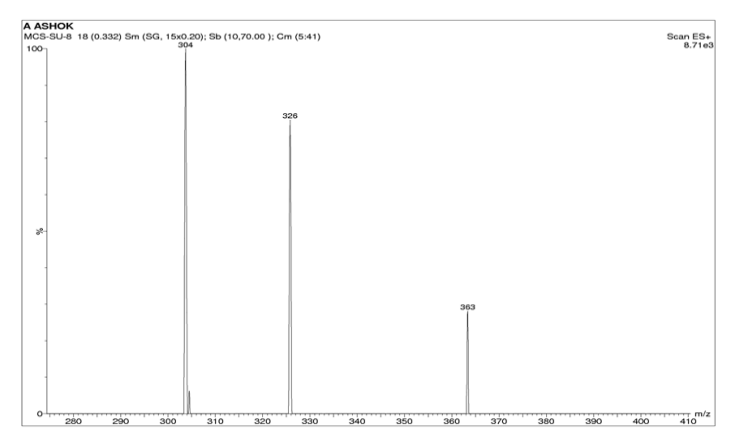

Fig. 7. Mass Spectrum of THBPTSC

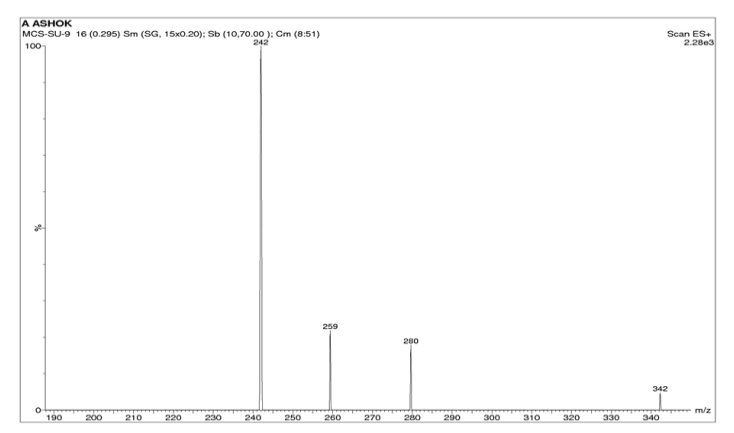

Fig. 8. Mass Spectrum of THBMTSC

chelating agents can be used for the chelation with $\mathrm{Cu}(\mathrm{II})$ metal ions. The biological activities of both the chelating agents and their metal complexes will be evaluated in our future studies.

\section{ACKNOWLEDGMENT}

This research did not receive any specific grant from funding agencies in the public, commercial, or not-for-profit sectors.

\section{REFERENCES}

1. Salsi, F.; Portapilla, G.B.; Schutjajew, K.; Carneiro, Z.A.; Hagenbach, A.; Albuquerque,
S.; Maia, P.I.D.; Abram, U. J. Fluorine Chem., 2018, 215, 52-61. 
2. Sens, L.; De Souza, A.C.A.;Pacheco, L.A.; Menegatti, A.C.O.; Mori, M.; Mascarello, A.; Junes, R.J.; Terenzi, H. Bioorg.Med. Chem., 2018, In press.

3. Deng, J.; Yu, P.; Zhang, Z.; Wang, J.; Cai, J.; Wu, N.; Sun, H.; Liang, H.; Yang, F. European J. Med. Chem., 2018, 158, 442-452.

4. Haldys, K.; Goldeman, W.; Jewginski, M.; Wolirinska, E.; Anger, N.; Rossowska, J.; Latajka, R. Bioorg. Chem., 2018, 81, 577-586.

5. Kallus, S.; Uhlik, L.; Schoonhoven, S.V.; Pelivan, K.; Berger, W.; Enyedy, E.A.; Hofmann, T.; Hffeter, P.; Kowol, C.R.; Keppler, B.K. J. Inorg. Biochem., 2019, 190, 85-97.

6. Huseynova, M.; Taslimi, P.; Medjidov, A.; Farzaliyev, V.; Aliyeva, M.; Gondolova, G.; Sahin, O.;Yalcin, B.; Sujayev, A.; Orman, E.B.;
Ozkaya, A.R.; Gulcin, I. Polyhedron., 2018, 155, 25-33.

7. Zhang, H.H.; Chen, Y.; Zhang, A. Results in Physics., 2018, 11, 554-563.

8. Ibrahim, A.B.M.; Farh, M.K.; Mayer, P. Inorg. Chem. Commun., 2018, 94, 127-132.

9. Ibrahim, A.B.M.; Farh, M.K.; El-Gyar, S.A.; ELGahami, M.A.; Fouad, D.M.; Silva, F.; Santos, I.C.; Paulo, A. Inorg. Chem. Commun., 2018, 96, 194-201.

10. Temraz, M.G.; Elzahhar, P.A.; Bekhit, A.E.D.; Bekhit, A.A.; Labib, H.F.; Belal, A.S.F. Eur.J . Med. Chem., 2018, 151, 585-600.

11. Kallnowski, D.S.; Quach, P.; Richardson, D.R. Future Med. Chem., 2009, 1(6), 1143-1151.

12. Matesanz, A.; Souza, P. Mini Rev. Med. Chem., 2009, 9(12), 1389-1396. 